\title{
Educational level and 30-day outcomes after hospitalization for acute myocardial infarction in Italy
}

\author{
Gianluca Cafagna* and Chiara Seghieri
}

\begin{abstract}
Background: There is a growing interest in the factors that influence short-term mortality and readmission after hospitalization for acute myocardial infarction (AMI) since such outcomes are commonly considered as hospital performance measures. Socioeconomic status (SES) is one of the factors contributing to healthcare outcomes after hospitalization for AMI. However, no study has been published on education and 30-day readmission in Europe. The objective of this study is to examine the association between educational level and 30-day mortality and readmission among patients hospitalized for AMI in Tuscany (Italy).

Methods: A retrospective cohort study using data from hospital discharge records was conducted. The analysis included all patients discharged with a principal diagnosis of AMI between January 1, 2011, and November 30, 2014, from all hospitals in Tuscany. Educational level was categorized as low (no middle school diploma), mid (middle school diploma) and high (high school diploma or more). Three multilevel models were developed, sequentially controlling for patient-level socio-demographic and clinical variables and hospital-level variables. Patients were stratified by age ( $\leq 75$ and $>75$ years).
\end{abstract}

Results: Mortality analysis included 23,402 patients, readmission analysis included 22,181 patients. In both unadjusted and full-adjusted models, patients with a high education had lower odds of 30-day mortality compared to those patients with low education (OR age $\leq 75$ years $0.67,95 \%$ Cl:0.47-0.94; OR age $>75$ years 0.72 , 95\% Cl:0.54-0.95). With regard to 30-day readmission, only patients aged over 75 years with a high education had lower odds of short-term readmission compared to those patients with low education (OR age $>750.73$, 95\% Cl:0.58-0.93).

Conclusions: Among patients hospitalized in Tuscany for AMl, low levels of education were associated with increased odds of 30-day mortality for both age groups and increased odds of 30-day readmission only for patients aged over 75 years. Our findings suggest that the educational component should not be underestimated in order to improve short-term outcomes, which are considered as performance measures at the hospital level. Hospital managers might consider strategies that are sensitive to patients with low SES, such as providing post-hospitalization support to less-educated patients and promoting a healthier lifestyle, to improve both health equity and performance outcomes.

Keywords: Education, Socioeconomic status, Acute myocardial infarction, Short-term mortality, Short-term readmission, Italy, Health care outcomes, Hospital performance, Health equity, Health services research

\footnotetext{
* Correspondence: g.cafagna@sssup.it

Health and Management Laboratory (MeS Lab), Institute of Management,

Sant'Anna School of Advanced Studies, Piazza Martiri della Libertà, 24, Pisa,

Italy
} 


\section{Background}

Since 30-day outcomes after hospitalization for acute myocardial infarction (AMI) are commonly considered as hospital performance measures [1-3], hospitals and clinicians have shown increasing interest in understanding and improving factors associated with 30-day mortality and readmission rates $[4,5]$. Evidence suggests that short-term mortality for AMI, heart failure, and pneumonia closely predict short-term mortality for a variety of other surgical and medical conditions, thus highlighting the utility of these measures to reflect a broader quality of hospital performance [6].

Short-term readmission is also a proxy of avoidable adverse health outcomes with relevant cost implications. A literature review highlights that between 5 and $59 \%$ of short-term readmission could be avoided [7], while the cost to Medicare of unplanned readmissions was estimated to be $\$ 17.4$ billion per year [8]. Hence, efforts to deepen the understanding of factors that influence early mortality and readmission for AMI patients could help to both improve quality and reduce costs.

Socioeconomic status (SES) is one of the factors contributing to poor health care outcomes after hospitalization for AMI [9-13]. The educational level has been used as a proxy for SES and is a strong predictor of both short-term [4, 14-20] and long-term outcomes [21-23]. Several studies have analysed the association between education and short-term mortality, but evidence is still needed in universal health care systems, which should guarantee equity in health by mandate. Furthermore, to the best of our knowledge no evidence has been provided on education and shortterm readmission in Europe.

In 2005, Tuscany became one of the few regions in Italy to develop a Performance Evaluation System (PES) based on the systematic collection of hospital performance indicators from administrative data sources [24]. Equity indicators were included in the Tuscan data monitoring process in 2008, and educational status was part of the SES information monitored in the hospitalization records of all Tuscan providers. In 2010 equity indicators were introduced into the Tuscan PES and in the planning and strategic control system of the Tuscan health care organizations [25]. The Tuscan PES is increasingly developing its equity dimension, making Tuscany an optimal location for carrying out the present study.

This research aims to provide context-specific evidence to extend the knowledge on and improve the understanding of SES factors associated with short-term outcomes after hospitalization for AMI. We therefore examined the association between educational level and 30-day mortality and readmission among patients hospitalized for AMI in Tuscany.

\section{Methods}

\section{Data}

We conducted a retrospective cohort study using data from hospital discharge records (HDRs). The analysis included all patients discharged with primary International Classification of Diseases, 9th revision, Clinical Modification (ICD-9-CM) codes of AMI between January 1, 2011, and November 30, 2014, from all hospitals in Tuscany. HDR data quality is routinely checked by the Regional Health Information System Office, which provides hospitals with feedback on missing data and logical inconsistencies.

Records were excluded based on criteria previously used elsewhere [26, 27]:

1) Admissions lasting less than two days - due to concerns about the accuracy of the diagnosis;

2) Admissions of patients not resident in Tuscany;

3) A diagnostic code 410.9 - AMI of unspecified site;

4) A diagnostic code 410.x2 - subsequent "episode of care" for discharged patients

5) Admissions of patients under 18 years and over 100 years;

6) Admissions of patients discharged from hospitals with less than 10 AMI admissions per year.

In order to avoid selection bias, we selected the first AMI episode $[14,15,17]$, and only included patients that had a baseline evaluation of 1 year with no AMI. For the readmission analysis, we considered only unplanned readmission and excluded patients only if they died during hospitalization (1221), not if they were alive at least 30 days after discharge, in line with similar studies, the Centers for Medicare \& Medicaid Services, and the Tuscan Outcome Program $[9,28,29]$. In cases where patients incurred more than one admission during the first 30 days after discharge, we considered only the first readmission. If patients were transferred, both mortality and readmission were attributed to the hospital to which the patients were initially admitted [27]. In accordance with similar studies $[14,20]$, we excluded 1878 patients whose educational level had not been registered. The inclusion/exclusion for the mortality analysis are shown in Fig. 1.

The Regional Health Information System Office assigned each patient with a unique identifier, which was the same for all administrative databases, and does not disclose the patient's identity or other sensitive data. The study was performed in full compliance with Italian privacy laws. Approval by an Ethics Committee was unnecessary, given that we used data from HDRs.

\section{Outcomes and exposures}

In a departure from longitudinal studies, our outcomes of interest were short-term outcomes after AMI, which 


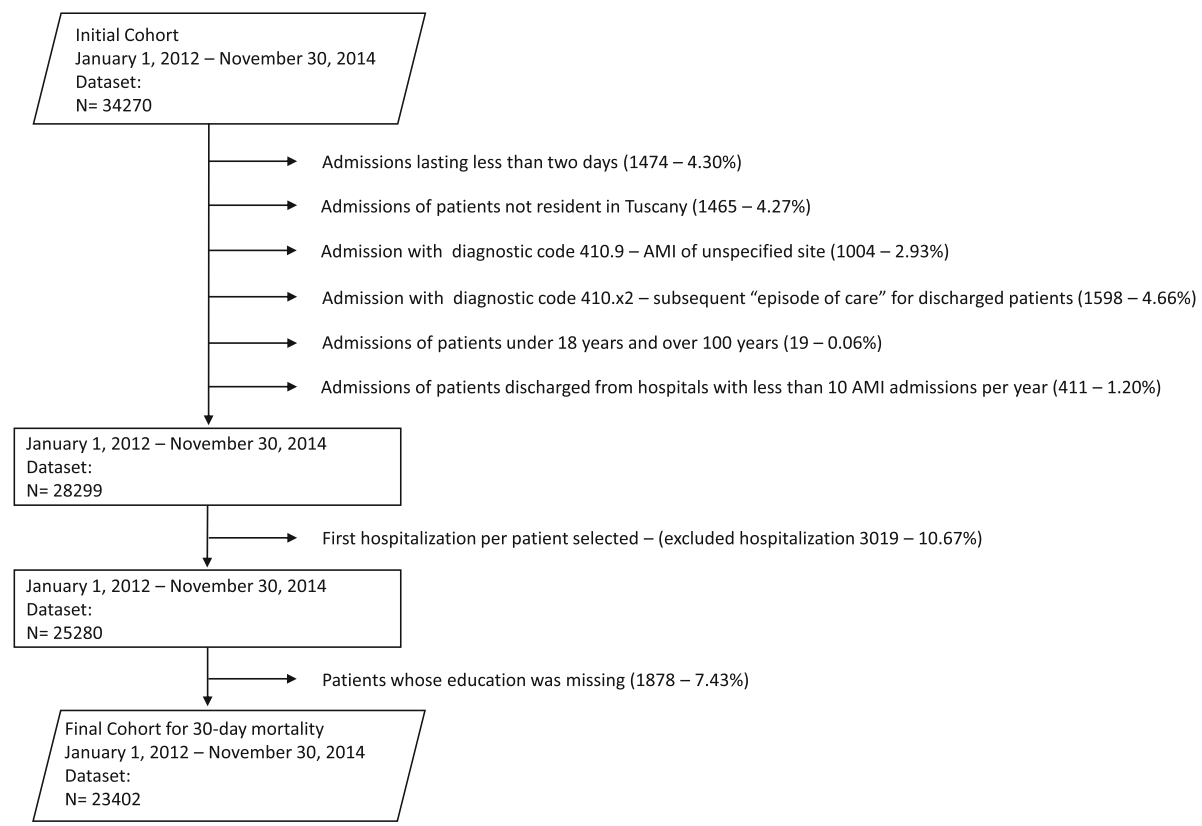

Fig. 1 AMl Cohort exclusions in the January 2012-November 2014 Dataset

are more relevant from a hospital performance perspective. 30-day mortality was defined as a death occurring due to any cause either during or after hospitalization within 30 days from the index admission; 30-day readmission was defined as a rehospitalisation occurring for any cause within 30 days of discharge. Information on mortality was obtained through a deterministic record linkage procedure between HDRs and the Tuscan residence registry, using the unique patient identifier. Similarly, follow-up was via record linkage of HDRs from all hospitals in Tuscany, using the unique patient identifier.

Data elements included socio-demographic variables, clinical variables and hospital variables. Socio-demographic variables (age, sex, and SES) were collected from the regional HDRs. We used the patient's individual level of education as a proxy for individual SES. Educational level was categorized as follows: low education (no middle school diploma), mid education (middle school diploma) and high education (high school diploma or more). These categories were defined on the basis of the birth cohort [30]. Given that patients' median age was 74 years and just $3.12 \%$ of patients included in the mortality analysis had a university degree, it seemed reasonable to consider both people with a high school diploma and people with a university degree under the same category (high education).

Clinical variables included the presence or absence of previous AMI episodes, type of ST-segment elevation (STEMI/NSTEMI), and specific patient comorbidities.
The type of ST-segment elevation was the best proxy available to us for AMI severity. The ICD-9-CM codes recorded in the previous 2 years were used to define specific patient comorbidities (tumours, diabetes, hematologic diseases, hypertensive diseases, other forms of ischemic heart diseases, heart failures, other cardiac conditions, conduction disorders and cardiac dysrhythmias, cerebrovascular diseases, vascular diseases, chronic obstructive pulmonary disease, and chronic nephropathies).

Hospital variables (teaching status and presence or absence of cardiac catheterisation laboratory) were included in the analysis, because they might confound the association between education and short-term outcomes. A cardiac catheterisation laboratory operates in hospitals equipped with relevant surgical support, and provides diagnosis and therapy services for various cardiovascular diseases [27].

\section{Statistical analysis}

Hierarchical logistic regression models, also known as multilevel models, were fitted due to the hierarchical structure of our data (i.e. patients nested within hospitals), in line with other studies [9]. In fact, "multilevel modes are used to take into account the effects of clustering of patients into hospitals and of hospital characteristics, that may affect short-term mortality" [27]. 30-day mortality and 30-day readmission are short-term outcomes considered as performance measures at the hospital level. We were interested in these outcomes 
because our final aim is to contribute to making hospital managers aware of the influence of individual SES on performance measures, which are used in public reporting. On a similar note, we decided to perform logistic regression models and not survival models because public reporting authorities, such as the Centers for Medicare \& Medicaid Services in the USA [29], and National Outcome Program in Italy [31, 32], perform logistic models to estimate risk-adjusted short-term mortality or readmission rates. Moreover, 30-day mortality and 30-day readmission are dichotomous outcomes, indicating whether or not the patient died or was readmitted within 30 days. Logistic regression models match the dichotomous nature of our outcomes and have been extensively used by other scholars for shortterm outcomes $[9,15,31]$. In order to test an alternative specification, we also performed survival models. The results using survival models were consistent with the results using logistic models.

Three two-level models were fitted for both the mortality and readmission analysis. The first model was unadjusted, including only the patients' individual level of education; the second model was adjusted for patients' age, sex, and clinical characteristics; the final model also included hospital characteristics. The analysis was stratified into two age groups: under 75 years and over 75 years. Hierarchical logistic regression models yielded odds ratios (ORs) with 95\% confidence intervals (CIs) for both patient-level and hospital-level variables. In order to estimate ORs for the individual level of education, we used low education as the reference category.

We also performed a specific analysis to assess the number of patients hospitalized for AMI in Tuscany and readmitted within 30 days of discharge in other Italian regions. It turned out that, over the study period, just 50 patients $(0.22 \%)$ were readmitted elsewhere in Italy, having no impact on our results. The limited number of Tuscan patients readmitted in other Italian regions could be explained by the fact that readmissions might be related to unplanned health events or that the Tuscan health care system is recognized as one of the best in Italy [33] and thus patients prefer to receive health care services in Tuscany.

$P$ value $<0.05$ was considered significant, and confidence intervals were calculated at $95 \%$. All analyses were carried out using SAS for Windows, version 9.3 (SAS Institute, Cary, NC) and STATA, version 13 (StataCorp LP, College Station, TX).

\section{Results}

\section{Baseline}

The mortality analysis included 23,402 patients; the readmission analysis included 22,181 patients. HDRs were extracted from 34 hospitals, of which 16 (47.1\%) had a cardiac catheterization laboratory and 5 (14.7\%) were teaching hospitals. The overall crude 30-day mortality was $7.0 \%, 2.5 \%$ among patients under 75 years, and $12.1 \%$ among those over 75 years. The overall crude 30 -day readmission was $12.3 \%, 9.6 \%$ among patients under 75 years, and $15.7 \%$ among those over 75 years.

Patients with a low education had a significantly higher 30-day mortality and readmission than patients with a high education, in both age groups. In addition, patients with a lower education were significantly older, more often women, had more comorbidities, had more previous AMI episodes, and had more STEMI type of AMI compared to patients with higher education.

Tables 1 and 2 show the patients' characteristics (clinical and demographic) stratified by age and educational level for mortality and readmission analysis, respectively.

\section{Mortality analysis}

Educational inequalities were found in 30-day mortality for AMI patients hospitalized in Tuscany. In both unadjusted and full-adjusted models, educational inequalities among patients under 75 years were stronger than those over 75 years.

In the unadjusted model (model 1), both patients with mid and high education had lower odds of 30-day mortality than patients with low education. In particular, patients under 75 years with a high education had a $57 \%$ decreased odds of 30-day mortality compared to those under 75 years with a low education. Patients over 75 years with a high education had a $40 \%$ decreased odds of 30-day mortality compared to those over 75 years with a low education. After adjusting for demographic and clinical characteristics (model 2), the educational inequalities were attenuated, and remained significant only by comparing the higher educated group with the lower one (OR age $\leq 75$ 0.68, 95\% CI: 0.48-0.96; OR age $>750.72,95 \% \mathrm{CI}: 0.54-0.95)$. In the full-adjusted model (model 3), there was no relevant change in the association between educational level and 30-day mortality (OR age $\leq 75$ 0.67, 95\% CI: $0.47-0.94$; OR age > 75 0.72, 95\% CI: 0.54-0.95).

\section{Readmission analysis}

Unlike the mortality analysis, in the readmission analysis we found a significant association between educational level and short-term readmission only among patients aged over 75 years.

In the unadjusted model (model 1), the association between educational level and short-term readmission was significant for both age groups. Patients hospitalized for AMI aged both under and over 75 years with a high education had a 22 and $28 \%$ decreased odds of 30-day readmission, respectively compared to those patients 
Table 1 Mortality analysis: baseline characteristics of study population, stratified by age and education

\begin{tabular}{|c|c|c|c|c|c|c|c|c|c|c|c|c|c|c|c|}
\hline & \multicolumn{5}{|l|}{ Overall } & \multicolumn{5}{|c|}{ age $\leq 75$} & \multicolumn{5}{|c|}{ age $>75$} \\
\hline & \multicolumn{5}{|c|}{ Level of education } & \multicolumn{5}{|c|}{ Level of education } & \multicolumn{5}{|c|}{ Level of education } \\
\hline & All & Low & Mid & High & $\bar{p}$ & All & Low & Mid & High & $p$ & All & Low & Mid & High & $p$ \\
\hline Number & 23,402 & 12,613 & 6667 & 4122 & & 12,409 & 4128 & 4924 & 3357 & & 10,993 & 8485 & 1743 & 765 & \\
\hline$\%$ & 100 & 53.9 & 28.5 & 17.6 & & 100 & 33.3 & 39.7 & 27.0 & & 100 & 77.2 & 15.9 & 7.0 & \\
\hline \multicolumn{16}{|l|}{ Demographic variables } \\
\hline Age in years & 71.7 & 78.0 & 65.6 & 62.4 & * & 61.6 & 66.6 & 59.9 & 57.9 & $*$ & 83.2 & 83.6 & 81.7 & 81.9 & * \\
\hline Male (\%) & 63.6 & 53.4 & 73.2 & 79.4 & $*$ & 76.1 & 68.3 & 78.5 & 82.2 & * & 49.9 & 46.1 & 57.9 & 66.8 & * \\
\hline \multicolumn{16}{|l|}{ Clinical variables } \\
\hline Tumours (\%) & 5.6 & 6.1 & 5.4 & 4.7 & $*$ & 4.5 & 5.3 & 4.4 & 3.7 & $*$ & 6.9 & 6.4 & 8.1 & 9.0 & * \\
\hline Diabetes (\%) & 8.8 & 10.9 & 7.5 & 4.4 & * & 6.2 & 9.0 & 5.8 & 3.3 & * & 11.7 & 11.8 & 12.2 & 9.4 & \\
\hline Hematologic diseases (\%) & 6.7 & 8.9 & 4.6 & 3.2 & $*$ & 2.9 & 4.0 & 2.7 & 2.1 & $*$ & 10.9 & 11.3 & 10.2 & 8.0 & * \\
\hline Hypertensive diseases (\%) & 14.3 & 17.3 & 12.0 & 8.9 & * & 9.4 & 11.7 & 9.1 & 6.9 & * & 19.9 & 20.0 & 20.4 & 17.5 & \\
\hline Other forms of ischemic heart diseases (\%) & 11.6 & 13.7 & 10.0 & 7.7 & $*$ & 8.0 & 10.0 & 7.7 & 6.2 & * & 15.7 & 15.6 & 16.8 & 14.2 & \\
\hline Previous heart failures (\%) & 6.8 & 9.1 & 4.6 & 3.0 & * & 3.0 & 4.4 & 2.5 & 1.9 & * & 11.1 & 11.5 & 10.5 & 7.7 & * \\
\hline Other cardiac conditions (\%) & 2.6 & 3.2 & 2.0 & 1.9 & * & 1.4 & 2.0 & 1.2 & 0.9 & * & 4.1 & 3.8 & 4.2 & 6.3 & * \\
\hline Conduction disorders and cardiac dysrhythmias (\%) & 6.7 & 8.9 & 4.7 & 3.2 & * & 2.9 & 4.3 & 2.5 & 1.7 & * & 11.0 & 11.1 & 11.2 & 9.5 & \\
\hline Cerebrovascular diseases (\%) & 9.3 & 11.8 & 7.2 & 4.9 & * & 4.7 & 6.3 & 4.5 & 3.2 & * & 14.4 & 14.5 & 14.9 & 12.7 & \\
\hline Vascular diseases (\%) & 7.3 & 8.5 & 6.5 & 4.8 & * & 5.8 & 7.6 & 5.5 & 4.0 & * & 9.0 & 8.9 & 9.5 & 8.4 & \\
\hline Chronic obstructive pulmonary disease (\%) & 4.2 & 5.4 & 3.4 & 1.8 & * & 2.3 & 3.4 & 2.2 & 1.2 & * & 6.3 & 6.4 & 6.8 & 4.3 & \\
\hline Chronic nephropathies (\%) & 11.7 & 15.0 & 8.5 & 6.5 & * & 5.2 & 6.9 & 4.8 & 3.8 & * & 18.9 & 19.0 & 18.9 & 18.6 & \\
\hline NSTEMI (\%) & 53.9 & 58.9 & 48.9 & 46.7 & $*$ & 47.4 & 53.8 & 44.6 & 43.5 & * & 61.3 & 61.4 & 60.9 & 60.5 & \\
\hline Previous AMI episodes (\%) & 9.4 & 10.0 & 9.2 & 7.9 & * & 8.1 & 8.8 & 8.0 & 7.3 & $*$ & 10.9 & 10.6 & 12.6 & 10.3 & \\
\hline 30-day mortality (\%) & 7.0 & 9.8 & 4.3 & 2.8 & $*$ & 2.5 & 3.5 & 2.4 & 1.6 & $*$ & 12.1 & 13.0 & 9.8 & 8.2 & * \\
\hline
\end{tabular}

$p<0.05$ in test for trend between levels of education

Low education $=$ no middle school diploma, mid education $=$ middle school diploma, and high education $=$ high school diploma or more

with a low education. After adjusting for patient's demographic and clinical characteristics (model 2) and hospital characteristics (model 3), the association was not attenuated and remained significant only among the older group. In the full-adjusted model, patients aged over 75 years with a high education had a $27 \%$ decreased odds of 30-day mortality compared to those patients aged over 75 years with a low education (OR age $>750.73,95 \%$ CI: $0.58-0.93)$. The results are shown in Table 3 and 4, and Figs. 2 and 3.

\section{Discussion}

This study found that patients with a low education are more likely to die during the 30-days following hospitalization for AMI compared to patients with a high education, while only older patients with a low education are more likely to be readmitted in Tuscany. The association between educational level and shortterm outcomes remained significant after adjusting for patient and hospital variables.

We decided to stratify our analysis instead of using models that interact age with educational attainment because we were interested in presenting the effect of SES on short-term outcomes for the elderly, thereby covering a gap in the literature. A recent literature review on SES and hospital readmissions for heart failure and AMI [34] highlighted the need for more studies that focus on specific population of elderly patients. Stratification with the cut point at the age 75 allowed us to focus on the very elderly patients, who are more likely to be readmitted due to preventable patient-related response, such as lower self-management capacity after discharge [35-37]. As explained in detail below, differences in patient-related responses after hospitalization for AMI is considered as a possible explanatory mechanism for educational inequalities in short-term outcomes. Other studies on risk factors for hospital readmissions focused on patients aged more than 75 years for similar reasons [38-40].

Assessing the causal path between SES and short-term mortality and readmission was out of the scope of this study and we were unable to disentangle the explanatory mechanisms for educational inequalities in short-term outcomes, due to a lack of data. However, based on the 
Table 2 Readmission analysis: baseline characteristics of study population, stratified by age and education

\begin{tabular}{|c|c|c|c|c|c|c|c|c|c|c|c|c|c|c|c|}
\hline & \multicolumn{5}{|l|}{ Overall } & \multicolumn{5}{|c|}{ age $\leq 75$} & \multicolumn{5}{|c|}{ age $>75$} \\
\hline & \multicolumn{5}{|c|}{ Level of education } & \multicolumn{5}{|c|}{ Level of education } & \multicolumn{5}{|c|}{ Level of education } \\
\hline & All & Low & Mid & High & $p$ & All & Low & Mid & High & $p$ & All & Low & Mid & High & $p$ \\
\hline Number & 22,181 & 11,692 & 6451 & 4038 & & 12,174 & 4020 & 4834 & 3320 & & 10,007 & 7672 & 1617 & 718 & \\
\hline$\%$ & 100 & 52.7 & 29.1 & 18.2 & & 100 & 33.0 & 39.7 & 27.3 & & 100 & 76.7 & 16.2 & 7.2 & \\
\hline \multicolumn{16}{|l|}{ Demographic variables } \\
\hline Age in years & 71.2 & 77.6 & 65.2 & 62.1 & $*$ & 61.5 & 66.5 & 59.9 & 57.9 & $*$ & 82.9 & 83.4 & 81.4 & 81.8 & * \\
\hline Male (\%) & 64.4 & 54.1 & 73.6 & 79.5 & $*$ & 76.2 & 68.3 & 78.6 & 82.3 & * & 50.0 & 46.6 & 58.5 & 67.0 & * \\
\hline \multicolumn{16}{|l|}{ Clinical variables } \\
\hline Tumours (\%) & 5.3 & 5.8 & 5.0 & 4.5 & $*$ & 4.3 & 5.0 & 4.2 & 3.6 & $*$ & 6.6 & 6.2 & 7.3 & 8.9 & * \\
\hline Diabetes (\%) & 8.4 & 10.5 & 7.3 & 4.2 & $*$ & 6.0 & 8.7 & 5.7 & 3.2 & * & 11.3 & 11.4 & 12.2 & 8.6 & \\
\hline Hematologic diseases (\%) & 6.4 & 8.7 & 4.4 & 3.0 & $*$ & 2.8 & 3.8 & 2.6 & 2.0 & $*$ & 10.8 & 11.2 & 9.9 & 7.5 & * \\
\hline Hypertensive diseases (\%) & 14.0 & 17.0 & 11.8 & 8.8 & $*$ & 9.3 & 11.5 & 9.0 & 7.0 & * & 19.7 & 19.9 & 19.9 & 17.1 & \\
\hline Other forms of ischemic heart diseases (\%) & 11.4 & 13.6 & 9.9 & 7.7 & $*$ & 8.0 & 9.9 & 7.6 & 6.2 & * & 15.6 & 15.5 & 16.7 & 14.3 & \\
\hline Previous heart failures (\%) & 6.3 & 8.6 & 4.3 & 2.9 & * & 2.9 & 4.2 & 2.4 & 1.9 & * & 10.5 & 10.9 & 9.8 & 7.4 & * \\
\hline Other cardiac conditions (\%) & 2.6 & 3.2 & 1.9 & 1.8 & $*$ & 1.3 & 2.0 & 1.2 & 0.8 & * & 4.0 & 3.8 & 4.3 & 6.0 & * \\
\hline Conduction disorders and cardiac dysrhythmias (\%) & 6.3 & 8.5 & 4.5 & 3.0 & * & 2.8 & 4.2 & 2.4 & 1.7 & * & 10.6 & 10.7 & 11.0 & 8.8 & \\
\hline Cerebrovascular diseases (\%) & 8.8 & 11.2 & 7.0 & 4.8 & $*$ & 4.6 & 6.1 & 4.3 & 3.1 & * & 14.0 & 13.9 & 15.0 & 12.3 & \\
\hline Vascular diseases (\%) & 7.1 & 8.4 & 6.2 & 4.7 & * & 5.6 & 7.3 & 5.3 & 3.9 & * & 8.9 & 9.0 & 9.1 & 8.1 & \\
\hline Chronic obstructive pulmonary disease (\%) & 4.0 & 5.2 & 3.3 & 1.7 & $*$ & 2.3 & 3.4 & 2.1 & 1.2 & * & 6.1 & 6.2 & 6.7 & 4.3 & \\
\hline Chronic nephropathies (\%) & 11.1 & 14.5 & 8.1 & 6.2 & * & 5.1 & 6.7 & 4.7 & 3.7 & * & 18.5 & 18.6 & 18.4 & 18.1 & \\
\hline NSTEMI (\%) & 55.0 & 60.8 & 49.5 & 47.1 & $*$ & 47.7 & 54.3 & 45.0 & 43.8 & * & 63.8 & 64.1 & 62.8 & 62.0 & \\
\hline Previous AMI episodes (\%) & 9.4 & 10.1 & 9.1 & 7.9 & * & 8.0 & 8.8 & 8.0 & 7.3 & $*$ & 11.1 & 10.8 & 12.6 & 10.4 & \\
\hline 30-day readmission (\%) & 12.3 & 14.4 & 10.5 & 9.2 & $*$ & 9.6 & 11.5 & 8.7 & 8.6 & $*$ & 15.7 & 16.0 & 15.8 & 12.0 & * \\
\hline
\end{tabular}

$p<0.05$ in test for trend between levels of education

Low education $=$ no middle school diploma, mid education $=$ middle school diploma, and high education $=$ high school diploma or more

existing related frameworks, we identify three possible explanatory mechanisms.

First, higher short-term mortality and readmission for less-educated AMI patients could be explained by differences in lifestyle, such as smoking, sleeping well, alcohol consumption, and amount of exercise. Patients with a higher SES are more likely to have a healthy lifestyle compared to patients with a lower SES [41, 42].

Second, inequalities in short-term outcomes might be caused by differences in acute care treatment [16]. In Denmark, for example, Rasmussen et al. found that patients with a higher SES were more likely to be performed a coronary artery bypass grafting compared to patients with a lower SES [43].

Third, differences in patient-related responses after hospitalization for AMI are also considered as a possible explanatory mechanism $[9,35,36,44-46]$. Differences in patient-related responses are associated with lower social capital and social cohesion [44] and lower selfmanagement capacity after discharge [35, 36]. Patients with a low education often have poor self-management skills, probably because they are less aware of the severity of symptoms and therapeutic measures and, consequently, less likely to turn instructions into practical measures, adhere to medication regimens, or obtaining follow-up care $[45,46]$. Differences in patientrelated responses after hospitalization for AMI appear to be particularly important in explaining readmission. Arbaje et al. found that patients lacking selfmanagement skills were more likely to be readmitted within 60 days after discharge among communitydwelling Medicare beneficiaries [35]. Hence, the fact that older patients have a lower self-management capacity and less social cohesion compared to younger patients [37] could justify our significant association between education and short-term readmission limited to patients over 75 years.

\section{Comparison with other studies}

The association between SES and short-term mortality has been examined using various SES measures, such as education, income [9], occupation [47], and deprivation [14]. We compared our findings above all with studies on education and short-term mortality conducted in 
Table 3 Odds ratios and 95\% confidence intervals for 30-day outcomes after hospitalization for AMI

\begin{tabular}{|c|c|c|c|c|c|c|}
\hline & \multicolumn{3}{|c|}{ 30-day mortality $(N=12,409)$} & \multicolumn{3}{|c|}{ 30-day readmission $(N=12,174)$} \\
\hline & Model 1 & Model 2 & Model 3 & Model 1 & Model 2 & Model 3 \\
\hline Low education & 1 & 1 & 1 & 1 & 1 & 1 \\
\hline Mid education & $0.68(0.53-0.87)$ & $0.94(0.72-1.22)$ & $0.94(0.72-1.22)$ & $0.77(0.66-0.88)$ & $0.91(0.78-1.06)$ & $0.91(0.78-1.06)$ \\
\hline High education & $0.43(0.31-0.59)$ & $0.68(0.48-0.96)$ & 0.67 (0.47 0.94) & $0.78(0.66-0.92)$ & $0.98(0.82-1.16)$ & $0.98(0.82-1.16)$ \\
\hline Male & - & $0.91(0.70-1.19)$ & $0.91(0.70-1.18)$ & - & $0.92(0.80-1.06)$ & $0.92(0.80-1.07)$ \\
\hline Age & - & $1.05(1.03-1.07)$ & $1.05(1.03-1.07)$ & - & $1.02(1.01-1.03)$ & $1.02(1.01-1.03)$ \\
\hline Tumours & - & $4.00(2.91-5.50)$ & $3.99(2.91-5.48)$ & - & $1.04(0.78-1.38)$ & $1.04(0.78-1.38)$ \\
\hline Diabetes & - & $1.26(0.82-1.92)$ & $1.23(0.81-1.88)$ & - & $1.18(0.90-1.53)$ & $1.18(0.90-1.53)$ \\
\hline Hematologic diseases & - & $2.08(1.36-3.18)$ & $2.08(1.36-3.17)$ & - & $1.13(0.80-1.58)$ & $1.12(0.80-1.57)$ \\
\hline Hypertensive diseases & - & $0.87(0.59-1.28)$ & $0.87(0.59-1.29)$ & - & $1.07(0.84-1.36)$ & $1.07(0.84-1.36)$ \\
\hline Other forms of ischemic heart diseases & - & $0.85(0.55-1.32)$ & $0.86(0.55-1.32)$ & - & $0.96(0.75-1.24)$ & $0.96(0.74-1.24)$ \\
\hline Previous heart failures & - & $1.79(1.06-3.04)$ & $1.80(1.06-3.06)$ & - & $1.55(1.11-2.18)$ & $1.54(1.10-2.17)$ \\
\hline Other cardiac conditions & - & $1.07(0.50-2.28)$ & $1.08(0.50-2.29)$ & - & $0.96(0.59-1.55)$ & $0.96(0.59-1.55)$ \\
\hline $\begin{array}{l}\text { Conduction disorders and cardiac } \\
\text { dysrhythmias }\end{array}$ & - & $1.45(0.86-2.44)$ & $1.41(0.84-2.39)$ & - & $0.88(0.62-1.26)$ & $0.89(0.62-1.26)$ \\
\hline Cerebrovascular diseases & - & $1.99(1.35-2.93)$ & $1.98(1.35-2.92)$ & - & $0.87(0.66-1.16)$ & $0.87(0.65-1.15)$ \\
\hline Vascular diseases & - & $1.97(1.38-2.82)$ & $1.95(1.36-2.78)$ & - & $1.35(1.06-1.72)$ & $1.35(1.06-1.72)$ \\
\hline Chronic obstructive pulmonary disease & - & $0.97(0.55-1.68)$ & $0.97(0.56-1.69)$ & - & $1.28(0.91-1.82)$ & $1.28(0.90-1.81)$ \\
\hline Chronic nephropathies & - & $1.57(1.05-2.35)$ & $1.61(1.08-2.40)$ & - & $1.59(1.25-2.02)$ & 1.59 (1.25-2.03) \\
\hline NSTEMI & - & $0.39(0.30-0.51)$ & $0.41(0.31-0.53)$ & - & $1.02(0.89-1.18)$ & $1.00(0.87-1.16)$ \\
\hline Previous AMl episodes & - & $1.07(0.71-1.61)$ & $1.04(0.69-1.56)$ & - & $0.94(0.74-1.18)$ & $0.94(0.74-1.18)$ \\
\hline Cathlab & - & - & $0.87(0.60-1.25)$ & - & - & $0.50(0.33-0.78)$ \\
\hline Teaching & - & - & $1.54(1.15-2.06)$ & - & - & $0.88(0.50-1.57)$ \\
\hline
\end{tabular}

Odds ratios reported from multilevel logistic regressions, the reference category is low education

Model 1: unadjusted

Model 2: model 1 adjusted for patients' age, sex, and clinical characteristics

Model 3: model 2 adjusted for hospital characteristics

Patients $\leq 75$ years old

European welfare state countries with universal health care systems, like the Italian one. Note that crude 30-day mortality after hospitalization for AMI in Tuscany (7.0\%) is lower than the average 30-day mortality in Europe, according to the OECD data (10.8\%) [48].

We identified studies conducted in Norway [16], Denmark [17], Finland [18, 19], and Italy [14, 15]. Overall, our findings are consistent with existing evidence, which showed a higher risk of death for lower educated patients, despite the efforts to promote equal access to health care typical of universal health care systems. Interestingly, the only studies showing a weak and inconsistent effect of individual education on short-term fatality were conducted in Italy $[14,15]$. However, other Italian studies, which used SES indicators but not education, confirmed SES inequalities in patients with AMI [47, 49, 50].

Similarly to the Finnish study [18], the effect of education on mortality was weaker for the older age group, but remained significant. The attenuation in the effect for the older group might be related to scarce prevention and unhealthy lifestyles at the time when older patients had been attending school. In addition, patients who survived until at least 75 years might be considered healthier than patients who died before, which might have reduced the effect of education on mortality among older patients (survival effect) [16]. In Norway and Denmark, a significant association was found only in the younger group of patients, while in our study it was found in both age groups. This could be explained by differences across the studies in the selection of the cutoff for the division of patients by age and in the definition of categories for the levels of education. We decided to consider both patients with a high school diploma and a university degree as high-educated patients, on the basis of our birth cohort [30].

To the best of our knowledge, no study has been published on education and short-term readmission in Europe. Available evidence is limited to the United States (US) and results are inconsistent. According to a systematic review on the influence of SES on hospital readmissions for heart failure and AMI in patients older 
Table 4 Odds ratios and 95\% confidence intervals for 30-day outcomes after hospitalization for AMI

\begin{tabular}{|c|c|c|c|c|c|c|}
\hline & \multicolumn{3}{|c|}{ 30-day mortality $(N=10,993)$} & \multicolumn{3}{|c|}{ 30-day readmission $(N=10,007)$} \\
\hline & Model 1 & Model 2 & Model 3 & Model 1 & Model 2 & Model 3 \\
\hline Low education & 1 & 1 & 1 & 1 & 1 & 1 \\
\hline Mid education & $0.74(0.62-0.88)$ & $0.87(0.73-1.05)$ & $0.88(0.73-1.05)$ & $1.03(0.88-1.20)$ & $1.02(0.87-1.19)$ & $1.02(0.87-1.18)$ \\
\hline High education & $0.60(0.46-0.79)$ & $0.72(0.54-0.95)$ & $0.72(0.54-0.95)$ & $0.72(0.57-0.91)$ & $0.73(0.57-0.93)$ & $0.73(0.58-0.93)$ \\
\hline Male & - & $1.05(0.93-1.20)$ & $1.06(0.93-1.20)$ & - & $1.05(0.94-1.18)$ & $1.05(0.94-1.18)$ \\
\hline Age & - & $1.11(1.10-1.12)$ & $1.11(1.10-1.12)$ & - & $1.00(0.99-1.01)$ & $1.00(0.99-1.01)$ \\
\hline Tumours & - & $1.86(1.50-2.29)$ & $1.85(1.50-2.28)$ & - & $1.09(0.88-1.35)$ & $1.09(0.88-1.35)$ \\
\hline Diabetes & - & $1.35(1.11-1.64)$ & $1.35(1.11-1.64)$ & - & $1.05(0.87-1.26)$ & $1.05(0.87-1.26)$ \\
\hline Hematologic diseases & - & $0.98(0.81-1.18)$ & $0.98(0.81-1.18)$ & - & $0.92(0.77-1.11)$ & $0.92(0.77-1.11)$ \\
\hline Hypertensive diseases & - & $0.78(0.66-0.93)$ & $0.78(0.66-0.93)$ & - & $1.01(0.86-1.18)$ & $1.01(0.87-1.18)$ \\
\hline Other forms of ischemic heart diseases & - & $0.94(0.78-1.14)$ & $0.94(0.78-1.14)$ & - & $1.15(0.97-1.36)$ & $1.15(0.97-1.36)$ \\
\hline Previous heart failures & - & $1.78(1.46-2.16)$ & $1.77(1.46-2.16)$ & - & $1.22(1.01-1.47)$ & $1.22(1.01-1.47)$ \\
\hline Other cardiac conditions & - & $0.99(0.72-1.35)$ & $0.98(0.72-1.34)$ & - & $0.73(0.54-0.98)$ & $0.72(0.54-0.98)$ \\
\hline $\begin{array}{l}\text { Conduction disorders and cardiac } \\
\text { dysrhythmias }\end{array}$ & - & $1.39(1.15-1.68)$ & $1.38(1.15-1.67)$ & - & $1.17(0.98-1.40)$ & $1.17(0.98-1.40)$ \\
\hline Cerebrovascular diseases & - & $1.56(1.33-1.83)$ & $1.55(1.32-1.82)$ & - & $1.16(0.99-1.35)$ & $1.15(0.99-1.35)$ \\
\hline Vascular diseases & - & $1.04(0.84-1.30)$ & $1.04(0.84-1.30)$ & - & $1.10(0.91-1.33)$ & $1.10(0.91-1.33)$ \\
\hline Chronic obstructive pulmonary disease & - & $1.19(0.94-1.50)$ & $1.18(0.94-1.50)$ & - & $1.03(0.83-1.29)$ & $1.03(0.82-1.29)$ \\
\hline Chronic nephropathies & - & $1.23(1.05-1.43)$ & $1.23(1.05-1.43)$ & - & $1.28(1.11-1.48)$ & $1.28(1.11-1.47)$ \\
\hline NSTEMI & - & $0.35(0.30-0.39)$ & $0.34(0.30-0.39)$ & - & $0.93(0.82-1.05)$ & $0.91(0.81-1.03)$ \\
\hline Previous AMl episodes & - & $0.83(0.67-1.03)$ & $0.83(0.67-1.03)$ & - & $1.03(0.86-1.23)$ & $1.03(0.86-1.23)$ \\
\hline Cathlab & - & - & $0.79(0.63-0.98)$ & - & - & $0.72(0.55-0.94)$ \\
\hline Teaching & - & - & $1.06(0.81-1.40)$ & - & - & $0.95(0.66-1.36)$ \\
\hline
\end{tabular}

Odds ratios reported from multilevel logistic regressions, the reference category is low education

Model 1: unadjusted

Model 2: model 1 adjusted for patients' age, sex, and clinical characteristics

Model 3: model 2 adjusted for hospital characteristics

Patients $>75$ years old

than 65 years [34], educational status was not associated with short-term readmission, based on the results of the US studies examined [51, 52]. However, other US studies showed that having a limited education was one of the factors associated with an increased risk of 30-day readmission [4].

\section{Policy implications}

Neither the measurement of inequalities [25] nor the impact of SES variables on quality performance measures have yet gained major managerial attention at the local or regional level. 30-day mortality and readmission are considered as performance measures at the hospital level. Recognizing the role of individual SES contributes to making hospitals aware of the influence of SES on their health care outcomes, which are subject to performance evaluation. This awareness could motivate hospitals to improve their performance outcomes through strategies that take into account individual SES.

Our findings suggest that the educational component should not be underestimated in attempts to improve short-term outcomes after hospitalization for AMI and decrease unnecessary costs [4]. Particular attention should be given to older patients with low education in order to reduce early readmission. Note that, over the study period, the estimated cost of unplanned readmissions to hospitals in Tuscany taken as a whole was $€ 9,196,891$. This crude estimation is derived by multiplying the total number of unplanned readmissions of our cohort of AMI patients during the study period by the median readmission cost as measured in terms of diagnosis-related group tariffs.

Hospital managers and policy makers, especially in universal health care systems, might be interested in strategies that are sensitive to low-educated patients in order to improve 30-day outcomes following hospitalization for AMI. These strategies include: promotion of healthier life styles, hospital-initiated transitional care [53, 54], and post-hospitalization support, such as follow-up for disadvantaged patients [55] and patient-centred adherence intervention [56]. These strategies are not mutually exclusive and their effectiveness 


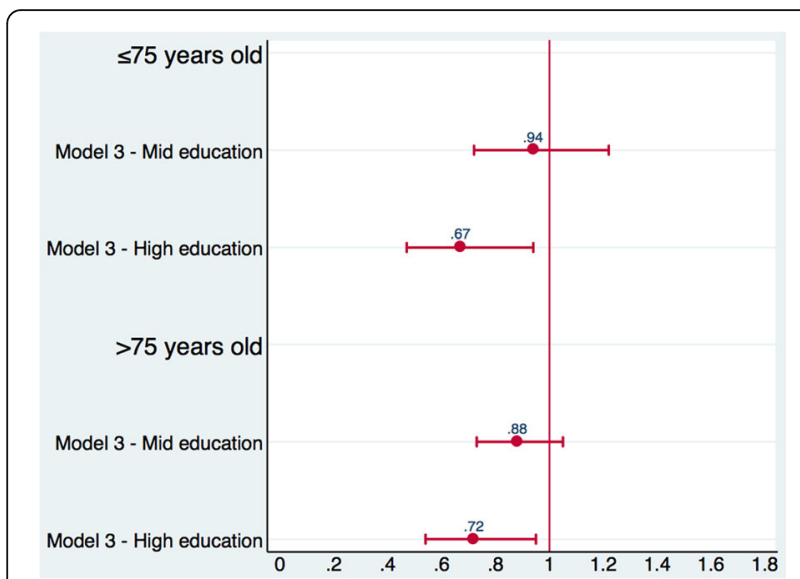

Fig. 2 Odds ratios (95\% Cls) for 30-day mortality. Legend: Odds ratios and $95 \%$ confidence intervals reported from multilevel logistic regressions for 30-day mortality. Low education is the reference category, which is compared with mid education and high education. Model $3=$ model adjusted for patients' age, sex, and clinical characteristics, and for hospital characteristics. Results are reported for patients aged both under and over 75 years

finds support in the literature. Given the scope of this study and the data at our disposal, it was impossible to define which strategy should be prioritized by hospital managers and policy makers. However, our results clearly indicate the need for increased attention to elderly patients with lower levels of education, especially regarding 30-day readmission. Post-hospitalization support strategies have the potential to be particularly effective for elderly patients with less education, because they increase patient understanding of symptoms and therapeutic

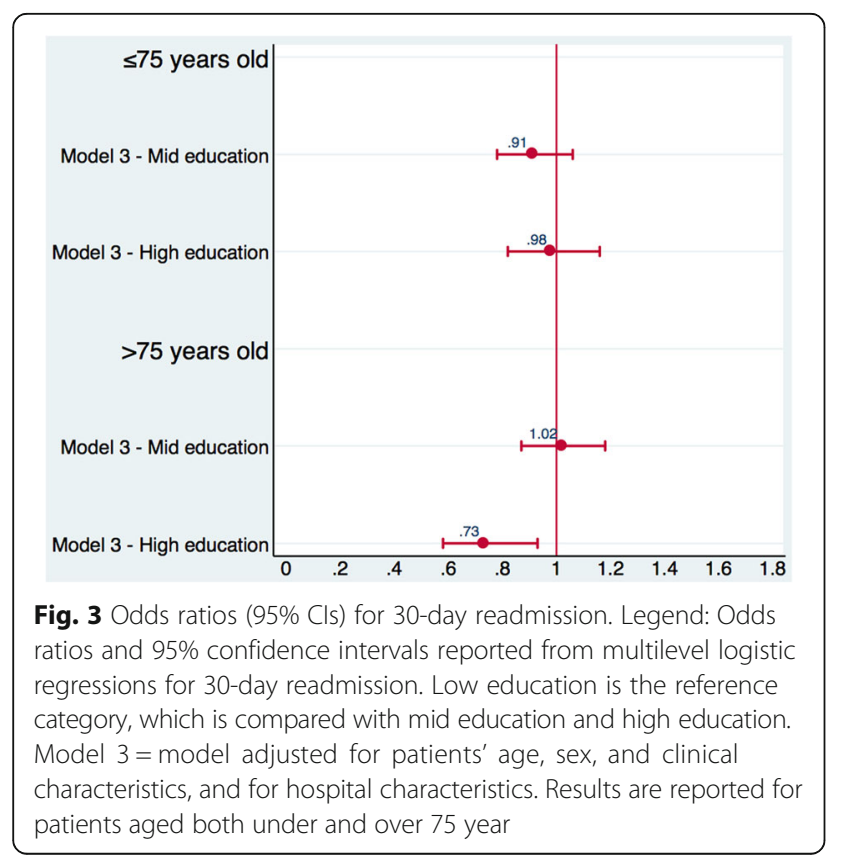

measures, and adherence to medication regimens, thus influencing patient response after discharge.

Future research is needed to support hospital managers and policy makers in defining which strategy sensitive to low-educated patients should be prioritized. In this sense, studies on the comparative effectiveness of different strategies would be useful, as well as qualitative studies to disentangle the explanatory mechanisms for educational inequalities in short-term outcomes.

Our analysis also supports Damiani et al. [34] who claimed for the introduction of indicators to measure and understand the role of SES inequalities in the risk for mortality and readmission. In particular, supplementing unadjusted measures with outcomes stratified by SES groups might be useful in motivating quality improvements at the hospital level and targeting efforts towards disadvantaged patients [57].

\section{Strengths and limitations}

This paper has several strengths. First, to the best of our knowledge, this is the first study in Europe exploring the association between individual education and 30-day readmission after hospitalization for AMI, which is particularly important in view of the limited understanding and the increased interest in this hospital quality indicator [58]. Second, we were able to include both individual variables (socio-demographic and clinical) and hospital variables in our models. As a consequence, similar to the most robust studies $[8,9,59]$, it was possible to adjust the associations between educational level and shortterm outcomes for the hospital characteristics. Third, educational status was measured at the individual level and was divided into three categories, taking into account the birth cohort of AMI patients for the definition of categories. By using an individual-level indicator instead of an area-based measure, we avoided the ecological fallacy. Note that information on education registered at HDRs has been considered as valid and fairly reliable [60].

This study has also some limitations. First, because data were collected from HDRs, it was impossible to consider all potential confounding variables. As with other studies using administrative data $[9,16]$, we lacked information on AMI severity, lifestyle factors such as smoking or alcohol consumption, treatment adherence, and procedural characteristics. Second, it is possible that comorbidities are unreported in some hospitals, which could lead to an overestimation of the educational effect [27]. Third, although education proved to be a good SES proxy for AMI short-term outcomes, our assessment of SES was based entirely on education [21]. We could not consider SES variables other than education, nor the interactions 
among them, which could provide a more comprehensive picture of individual levels of SES.

\section{Conclusions}

We found an association between educational level and 30-day mortality and readmission among patients hospitalized for AMI in Tuscany. For the 30-day readmission analysis, a significant association was limited to patients over 75 years. Our results suggest that hospitals might consider strategies that are sensitive to low SES patients to improve both health equity and their performance measures. Further research is needed to provide comparable evidence in other European universal health care systems, especially in terms of readmission analysis, and to assess the association between SES and other outcomes, considered as quality indicators at the hospital level.

\begin{abstract}
Abbreviations
AMl: Acute myocardial infarction; Cl: Confidence interval; HDR: Hospital discharge record; ICD-9-CM: International classification of diseases, 9th revision, clinical modification; OECD: Organization for Economic Co-operation and Development; OR: Odds ratio; PES: Performance evaluation system; SES: Socioeconomic status; US: United States

\section{Acknowledgements}

The authors thank the European Health Policy Group (EHPG) for their valuable comments and Ana Rico Gómez for her kind and insightful suggestions. The authors also thank the reviewer that contributed to improve the manuscript and better clarify some points. The authors acknowledge Professor Sabina Nuti and all researchers from "Laboratorio Management e Sanitá" (MeS Lab), Institute of Management, Sant'Anna School of Advances Studies, for their constant support and useful comments. Finally, the authors thank Adrian Wallwork for editing the English.
\end{abstract}

\section{Funding}

The authors received no specific funding for this work.

\section{Availability of data and materials}

The data used in the study are from hospital discharge records of the Tuscany Region and are not publicly available. Access to data to the Scuola Superiore Sant'Anna, Pisa (Italy) was allowed within the Decree $n^{\circ} 544$ of the year 2010 of the Tuscany Region and Decree $n^{\circ} 157$ of the year 2010 of the Scuola Superiore Sant'Anna, Pisa (Italy).

\section{Authors' contributions}

All the authors were involved in the design of this study. GC wrote the manuscript, which was critically revised by CS. CS analysed the data with the support of GC. All authors contributed to the data interpretation. Both authors read and approved the final version of the manuscript.

\section{Competing interests}

The authors declare that they have no competing interests.

\section{Consent for publication}

Not applicable.

\section{Ethics approval and consent to participate}

The Regional Health Information System Office assigned each patient with a unique identifier, which does not disclose the patient's identity. The study was performed in full compliance with Italian laws and approval by an Ethics Committee was unnecessary.

Received: 28 April 2016 Accepted: 21 December 2016 Published online: 09 January 2017

\section{References}

1. Krumholz HM, Normand S-LT, Spertus JA, Shahian DM, Bradley EH. Measuring performance for treating heart attacks and heart failure: the case for outcomes measurement. Health Aff. 2007:26:75-85.

2. Krumholz HM, Merrill AR, Schone EM, Schreiner GC, Chen J, Bradley EH, et al. Patterns of hospital performance in acute myocardial infarction and heart failure 30-day mortality and readmission. Circ Cardiovasc Qual Outcomes. 2009;2:407-13.

3. Axon RN, Williams MV. Hospital readmission as an accountability measure. JAMA. 2011;305:504-5.

4. Khawaja FJ, Shah ND, Lennon RJ, Slusser JP, Alkatib AA, Rihal CS, et al. Factors associated with 30-day readmission rates after percutaneous coronary intervention. Arch Intern Med. 2012;172:112-7.

5. Herrin J, St. Andre J, Kenward K, Joshi MS, Audet AMJ, Hines SC. Community factors and hospital readmission rates. Health Serv Res. 2015;50:20-39.

6. Mc Crum ML, Joynt KE, Orav EJ, Gawande AA, Jha AK. Mortality for publicly reported conditions and overall hospital mortality rates. JAMA Intern Med. 2013;173:1351-7.

7. Nolte E, Roland M, Guthrie S, Brereton L. Preventing emergency readmissions to hospital: a scoping review. Santa Monica: Rand Corporation; 2012.

8. Jencks SF, Williams MV, Coleman EA. Rehospitalizations among patients in the Medicare fee-for-service program. N Engl J Med. 2009;360:1418-28.

9. Lindenauer PK, Lagu T, Rothberg MB, Avrunin J, Pekow PS, Wang Y, et al. Income inequality and 30 day outcomes after acute myocardial infarction, heart failure, and pneumonia: retrospective cohort study. BMJ. 2013;346:f521.

10. Bernheim SM, Spertus JA, Reid KJ, Bradley EH, Desai RA, Peterson ED, et al. Socioeconomic disparities in outcomes after acute myocardial infarction. Am Heart J. 2007;153:313-9.

11. Shen JJ, Wan TT, Perlin JB. An exploration of the complex relationship of socioecologic factors in the treatment and outcomes of acute myocardial infarction in disadvantaged populations. Health Serv Res. 2001;36:711-32.

12. Alter DA, Naylor CD, Austin P, Tu JV. Effects of socioeconomic status on access to invasive cardiac procedures and on mortality after acute myocardial infarction. N Engl J Med. 1999;341:1359-67.

13. Wang JY, Wang CY, Juang SY, Huang KY, Chou P, Chen CW, et al. Low socioeconomic status increases short-term mortality of acute myocardial infarction despite universal health coverage. Int J Cardiol. 2014;172:82-7.

14. Picciotto S, Forastiere F, Stafoggia M, D'Ippoliti D, Ancona C, Perucci C. Associations of area based deprivation status and individual educational attainment with incidence, treatment, and prognosis of first coronary event in Rome, Italy. J Epidemiol Community Health. 2006;60:37-43.

15. Gnavi R, Rusciani R, Dalmasso M, Giammaria M, Anselmino M, Roggeri DP, et al. Gender, socioeconomic position, revascularization procedures and mortality in patients presenting with STEMI and NSTEMI in the era of primary PCI. Differences or inequities? Int J Cardiol. 2014;176:724-30.

16. Igland J, Vollset SE, Nygård OK, Sulo G, Sulo E, Ebbing M, et al. Educational inequalities in 28day and 1-year mortality after hospitalisation for incident acute myocardial infarction - a nationwide cohort study. Int J Cardiol. 2014;177:874-80.

17. Rasmussen JN, Rasmussen S, Gislason GH, Buch P, Abildstrom SZ, Køber L, et al. Mortality after acute myocardial infarction according to income and education. J Epidemiol Community Health. 2006;60:351-6.

18. Lammintausta A, Immonen-Räihä P, Airaksinen JKE, Torppa J, Harald K, Ketonen $\mathrm{M}$, et al. Socioeconomic inequalities in the morbidity and mortality of acute coronary events in Finland: 1988 to 2002. Ann Epidemiol. 2012;22:87-93.

19. Salomaa $V$, Niemelä $M$, Miettinen $H$, Ketonen $M$, Immonen-Räihä $P$, Koskinen S, et al. Prehospital, 28-day, and 1-year mortality rates of acute infarction register study. Circulation. 2000;101:1913-8.

20. Pilote L, Tu JV, Humphries K, Behouli H, Belisle P, Austin PC, et al. Socioeconomic status, access to health care, and outcomes after acute myocardial infarction in Canada's universal health care system. Med Care. 2007:45:638-46.

21. Kirchberger I, Meisinger C, Golüke H, Heier M, Kuch B, Peters A, et al. Longterm survival among older patients with myocardial infarction differs by educational level: results from the MONICA/KORA myocardial infarction registry. Int J Equity Health. 2014;13:19.

22. Donyavi T, Naieni KH, Nedjat S, Vahdaninia M, Najafi M, Montazeri A. Socioeconomic status and mortality after acute myocardial infarction: a study from Iran. Int J Equity Health. 2011;10:9. 
23. Coady SA, Johnson NJ, Hakes JK, Sorlie PD. Individual education, area income, and mortality and recurrence of myocardial infarction in a Medicare cohort: the National Longitudinal Mortality Study. BMC Public Health. 2014;14:705.

24. Nuti S, Seghieri C, Vainieri M. Assessing the effectiveness of a performance evaluation system in the public health care sector: some novel evidence from the Tuscany region experience. J Manag Gov. 2013;17:59-69.

25. Barsanti S, Nuti S. The equity lens in the health care performance evaluation system. Int J Health Plann Manage. 2014;29:e233-46.

26. Renzi C, Asta F, Fusco D, Agabiti N, Davoli M, Perucci CA. Does public reporting improve the quality of hospital care for acute myocardial infarction? Results from a regional outcome evaluation program in Italy. Int J Qual Heal Care. 2014;26(3):223-30.

27. Seghieri C, Mimmi S, Lenzi J, Fantini MP. 30-day in-hospital mortality after acute myocardial infarction in Tuscany (Italy): an observational study using hospital discharge data. BMC Med Res Methodol. 2012;12:170.

28. Krumholz HM, Lin Z, Keenan PS, Chen J, Ross JS, Drye EE, et al. Relationship between hospital readmission and mortality rates for patients hospitalized with acute myocardial infarction, heart failure, or pneumonia. JAMA. 2013;309:587-93.

29. Krumholz HM, Normand ST, Keenan PS, Desai MM, Lin Z, Drye EE, et al. Hospital 30-day acute myocardial infarction readmission measure: methodology. Report prepared for the Centers for Medicare \& Medicaid Services. 2008.

30. Galobardes B, Shaw M, Lawlor DA, Lynch JW, Davey Smith G. Indicators of socioeconomic position (part 1). J Epidemiol Community Health. 2006;60:7-12.

31. Fusco D, Barone AP, Sorge C, D'Ovidio M, Stafoggia M, Lallo A, Davoli M, Perucci CA. P. Re.Val.E.: outcome research program for the evaluation of health care quality in Lazio, Italy. BMC Health Serv Res. 2012;12:25.

32. Ministero della Salute, Agenzia Nazionale per i Servizi Sanitari Regionali. Programma Nazionale Esiti - PNE. Edizione 2015. Metodi Statistici. 2015. http://95.110.213.190/PNEed15/main/doc/metodi_statistici.pdf. Accessed 6 Nov 2016.

33. Ministero della Salute. Adempimento "mantenimento dell'erogazione dei Lea" attraverso gli indicatori della griglia Lea. Metodologia e risultati dell'anno 2013. 2015. http://www.salute.gov.it/imgs/C_17_pubblicazioni 2397_allegato.pdf Accessed 6 Nov 2016.

34. Damiani G, Salvatori E, Silvestrini G. Influence of socioeconomic factors on hospital readmissions for heart failure and acute myocardial infarction in patients 65 years and older : evidence from a systematic review. Clin Interv Aging. 2015;10:237-45.

35. Arbaje Al, Wolff JL, Yu Q, Powe NR, Anderson GF, Boult C. Postdischarge environmental and socioeconomic factors and the likelihood of early hospital readmission among community-dwelling Medicare beneficiaries. Gerontologist. 2008;48:495-504.

36. Goldman DP, Smith JP. Can patient self-management help explain the SES health gradient? Proc Natl Acad Sci U S A. 2002;99:10929-34

37. Marek KD, Antle L. Medication management of the community-dwelling older adult. In: Hughes RG, editor. Patient safety and quality: an evidencebased handbook for nurses. Rockville: Agency for Healthcare Research and Quality (US); 2008. p. 22-30.

38. García-Pérez L, Linertová R, Lorenzo-Riera A, Vázquez-Díaz JR, DuqueGonzález B, Sarría-Santamera A. Risk factors for hospital readmissions in elderly patients: a systematic review. QJM. 2011;104:639-51.

39. Witherington EMA, Pirzada OM, Avery AJ. Communication gaps and readmissions to hospital for patients aged 75 years and older: observational study. Qual Saf Health Care. 2008;17:71-5.

40. Linertová R, García-Pérez L, Vázquez-Díaz JR, Lorenzo-Riera A, Sarría-Santamera A. Interventions to reduce hospital readmissions in the elderly: in-hospital or home care. A systematic review. J Eval Clin Pract. 2011;17:1167-75.

41. Chan RHM, Gordon NF, Chong A, Alter DA. Influence of socioeconomic status on lifestyle behavior modifications among survivors of acute myocardial infarction. Am J Cardiol. 2008;102:1583-8.

42. Contoyannis $\mathrm{P}$, Jones AM. Socio-economic status, health and lifestyle. J Health Econ. 2004;23:965-95.

43. Rasmussen JN, Rasmussen S, Gislason GH, Abildstrom SZ, Schramm TK Torp-Pedersen C, et al. Persistent socio-economic differences in revascularization after acute myocardial infarction despite a universal health care system - a Danish study. Cardiovasc Drugs Ther. 2007;21:449-57.

44. Kawachi I, Kennedy BP, Lochner K, Prothrow-Stith D. Social capital, income inequality, and mortality. Am J Public Health. 1997;87:1491-8.
45. Moser DK, Kimble LP, Alberts MJ, Alonzo A, Croft JB, Dracup K, et al. Reducing delay in seeking treatment by patients with acute coronary syndrome and stroke: a scientific statement from the American Heart Association Council on Cardiovascular Nursing and Stroke Council. Circulation. 2006;114:168-82.

46. Makaryus AN, Friedman EA. Patients' understanding of their treatment plans and diagnosis at discharge. Mayo Clin Proc. 2005;80:991-4.

47. Cesana G, Ferrario M, Gigante S, Sega R, Toso C, Achilli F. Socio-occupational differences in acute myocardial infarction case-fatality and coronary care in a northern Italian population. Int J Epidemiol. 2001;30 Suppl 1:S53-8.

48. OECD. Health at a glance 2013: OECD indicators. Paris: OECD Publ; 2013.

49. Alboni P, Amadei A, Scarfò S, Bettiol K, Ippolito F, Baggioni G. In industrialized nations, a low socioeconomic status represents an independent predictor of mortality in patients with acute myocardial infarction. Ital Heart J. 2003;4:551-8.

50. Ancona C, Arcà M, Saitto C, Agabiti N, Fusco D, Tancioni V, et al. Differences in access to coronary care unit among patients with acute myocardial infarction in Rome: old, ill, and poor people hold the burden of inefficiency. BMC Health Serv Res. 2004:4:34

51. Roe-Prior P. Sociodemographic variables predicting poor post-discharge outcomes for hospitalized elders with heart failure. Medsurg Nurs. 2007:16:317-21.

52. Schwarz KA, Elman CS. Identification of factors predictive of hospital readmissions for patients with heart failure. Heart Lung. 2003;32:88-99.

53. Coleman EA, Parry C, Chalmers S, Min S. The care transitions intervention. Arch Intern Med. 2006;166:1822-8.

54. Bettger JP, Alexander KP, Dolor RJ, Olson DM, Kendrick AS, Wing L, et al. Transitional care after hospitalization for acute stroke or myocardial infarction: a systematic review. Ann Intern Med. 2012;157:407-16.

55. Hernandez AF, Greiner MA, Fonarow GC, Hammill BG, Heidenreich PA, Yancy CW, et al. Relationship between early physician follow-up and 30-day readmission among Medicare beneficiaries hospitalized for heart failure. JAMA. 2010;303:1716-22.

56. Lambert-Kerzner A, Del Giacco EJ, Fahdi IE, Bryson CL, Melnyk SD, Bosworth $\mathrm{HB}$, et al. Patient-centered adherence intervention after acute coronary syndrome hospitalization. Circ Cardiovasc Qual Outcomes. 2012;5:571-6.

57. Jha AK, Zaslavsky AM. Quality reporting that addresses disparities in health care. JAMA. 2014;312:225-6.

58. Nuti SV, Wang Y, Masoudi FA, Bratzler DW, Bernheim SM, Murugiah K, et al. Improvements in the distribution of hospital performance for the care of patients with acute myocardial infarction, heart failure, and pneumonia, 2006-2011. Med Care. 2015;53:485-91.

59. Joynt KE, Orav EJ, Jha AK. Thirty-day readmission rates for Medicare beneficiaries by race and site of care. JAMA. 2011;305:675-81.

60. Ventura M, Colais P, Fusco D, Agabiti N, Cesaroni G, Davoli M. Information on educational level from hospital discharge register: an analysis of validity. Epidemiol Prev. 2013;37:289-96.

\section{Submit your next manuscript to BioMed Central and we will help you at every step:}

- We accept pre-submission inquiries

- Our selector tool helps you to find the most relevant journal

- We provide round the clock customer support

- Convenient online submission

- Thorough peer review

- Inclusion in PubMed and all major indexing services

- Maximum visibility for your research

Submit your manuscript at www.biomedcentral.com/submit 